\title{
Proteomics analysis of suckling mouse brain infected with attenuated rabies virus strain SRV9
}

\author{
W. YAN ${ }^{1,2,3 \dagger}$, R. XIANG ${ }^{1 \dagger}$, J. CHEN ${ }^{1 \dagger}$, C. HUANG ${ }^{3}$, Z.-G. YUAN ${ }^{4}, Y^{-}$HUANG $^{1}$, \\ S.-J. LUO ${ }^{1}$, Z. HUANG ${ }^{1}$, H. XIANG ${ }^{1 *}$ X.-H. WANG ${ }^{1 *}$
}

\begin{abstract}
${ }^{1}$ Key Laboratory of Livestock Disease Prevention of Guangdong Province, Scientific Observation and Experiment Station of Veterinary Drugs and Diagnostic Techniques of Guangdong Province, Ministry of Agriculture and Rural Affairs, Institute of Animal Health, Guangdong Academy of Agricultural Sciences, Guangzhou, Guangdong Province 510640, P. R. China; ${ }^{2}$ Institute of Tropical Medicine, Guangzhou University of Chinese Medicine, Guangzhou, 510405, P. R. China; ${ }^{3}$ Aix-Marseille Université, CNRS, INSERM, Marseille, France; ${ }^{4}$ College of Veterinary Medicine, South China Agricultural University, Guangzhou, Guangdong Province 510642, P. R. China
\end{abstract}

Received November 27, 2018; revised March 15, 2019; accepted September 23, 2019

\begin{abstract}
Summary. - Rabies virus is an enveloped negative-stranded RNA virus belonging to the family Rhabdoviridae. It can be successfully controlled by vaccination however, there are still tens of thousands of deaths each year caused by rabies virus due to its mutations and complexity. A better understanding of the interaction between the rabies virus and the host might help solve this problem. Therefore, in this study, we used two-dimensional electrophoresis to investigate the protein expression of rabies virus-infected mice. This can help us to understand the impact of rabies virus on host protein expression during infection. For our experiment, two-dimensional electrophoresis was used to analyze the differential proteomics of the brain of 10- and 20-day-old suckling mice infected with attenuated rabies virus strain SRV9. The results showed that the expression levels of 10 protein spots had been up- or down-regulated at least 2-fold. Using MALDI-TOF-MS, we identified 8 differentially expressed proteins. We have identified proteins, namely hnRNP L, DPYSL3, NECAPs, and transaldolase that might be closely related to the susceptibility of SRV9 in suckling mice.
\end{abstract}

Keywords: rabies virus; attenuated strain; suckling mouse; two-dimensional electrophoresis; proteomics

\section{Introduction}

Rabies is one of the epidemic zoonosis caused by rabies virus (RABV). The main clinical features of the infected

${ }^{*}$ Corresponding authors. E-mail: xianghua868@163.com (H. Xiang), wangxiaohu2020@163.com (X.-H. Wang); phone: +8620 85291469. ${ }^{\dagger} T h e s e$ authors contributed equally to this work. Abbreviations: $\mathrm{CyMDH}=$ cytosolic malate dehydrogenase; DPYSL3 = dihydropyrimidinase like 3; FBP = far upstream element binding protein; FUSE = far upstream element; HnRNP L = heterogenous nuclear ribonucleoprotein $\mathrm{L}$; $\mathrm{NADPH}=$ nicotinamide adenine dinucleotide phosphate; NECAPs = adaptin ear-binding clathrin-associated protein; $\mathrm{NmrA}=$ nitrogen metabolite repression regulator; $\mathrm{RABV}=$ rabies virus; $\mathrm{SDR}=$ short-chain dehydrogenase reductase superfamily homoeothermic organisms including human are acute lethal encephalomyelitis, progressive paralysis, and death. After sub-culturing in the animals, chicken embryos or cells, the virulence of some RABV strains may be gradually attenuated, however, the virulence of some RABV, such as Flury-LEP, Flury-HEP, ERA, SAD, B19, SAG1/2 strain, can gradually increase after adaptation in cells.

SRV9 has always been used in various studies for a RABV attenuated vaccine strains in China (Bourhy et al., 1992). In this study, we have used a medium plaque-forming strain derived from strain SAD B19 (Muller et al., 2006). Chinese rabies virus SRV9 strain is an attenuated vaccine strain derived from strain SAD. It has good immunogenicity and it is not pathogenic to most of the animals. RABV SRV9 after inoculation of 5-10 folds of the routine dose has no adverse reaction in the dogs, rats, guinea pigs, rhesus monkeys, and 
sika deer, improving thus the safety of intracerebral injection. Different doses were used to inoculate weaning and adult mice, and the results showed that after brain, muscle, subcutaneous or oral vaccination, the vaccines were safe and generated good immune responses (Schmidt et al., 2012). However, in some cases, patients still die after vaccination and the study of the RABV mechanism resistance should be investigated more. SRV9 is a popular and useful strain for these studies. In this work, we have intracerebrally inoculated SRV9 into 1- to 22-day-old suckling mice and found that all mice under age of 13 days died, some mice of 14 to 17 days of age died, while mice older than 18 days survived. Meanwhile, some studies reported that all the mice between 14 to 17 days of age after inoculation with SRV9 survived, indicating that the susceptibility to SRV9 appears to have a phasic change among the suckling mice with different ages.

The mechanism involved in RABV infection is very complex. Proteomics is one of the powerful tools to find diseaserelated proteins and reveal the pathogenicity mechanism. In the research of viral infections, proteomics can be used as an important tool to clarify the differential expression of proteins in tissues or cells at different infection stages. Using two-dimensional gel electrophoresis (2-DE), mass spectrometry (MS) identification, protein database analysis, and other proteomic technologies can help us confirm the differential expression of host cell-related proteins before and after viral infection (Pleissner et al., 2004).

To study the pathogenicity of the virus and molecules related to the response of host cells in the brain tissues of suckling mice of different age infected with RABV attenuated strain SRV9, we accomplished differential proteomics analysis of the SRV9 infected suckling mice's brain tissues and compared to the uninfected mice of the same age. Through this study, we found several proteins which are crucial for SRV9 infection and provide more information for the development of SRV9 vaccine.

\section{Materials and Methods}

Virus, animals, and reagents. RABV attenuated strain, SRV9 was provided by the epidemiology laboratory of Changchun Veterinary Research Institute of Academy of Military Medical Sciences. Chinese Kunming pregnant mice in the clean grade were purchased from Changchun Institute of Biological Products. Suckling mice of different ages were reproduced in the laboratory (No. 44005800000099). IPG buffer and IPG dry-strips (18 cm, pH 3-10; $18 \mathrm{~cm}, \mathrm{pH} 4-7)$ were purchased from GE Health (USA). Bovine serum albumin and trypsin inhibitor (complete Mini, EDTA-free) were purchased from Roche (USA). Goat anti-mouse IgG antibody labeled with horseradish peroxidase (HRP), goat anti-rabbit IgG antibody, HnRNP L and NECAP 1 (murine monoclonal antibo- dies), were purchased from Santa Cruz Biotechnology (USA). PVDF membrane was purchased from Millipore (USA). Chemiluminescence substrate kit was purchased from Pierce (USA).

Preparation of SRV9 brain virus suspension and determination of drug median lethal dose. Each gram of ground brain tissues of SRV9 infected suckling mice was suspended in $10 \mathrm{ml}$ of MEM medium with $10 \%$ FBS. After centrifugation, the supernatant was collected for $\mathrm{LD}_{50}$ determination. Brain tissue of uninfected suckling mouse was processed in the same way. $\mathrm{LD}_{50}$ determination was performed according to the reference (Wenqiang et al., 2014). We used the SRV9 virus to infect the brain of 3-day-old suckling mice and prepared the virus suspension from the fresh brain tissue, and then determined the $\mathrm{LD}_{50}$ in the 3-day-old suckling mice. According to the results, the virus suspension was stored as $100 \mathrm{LD}_{50} / 10 \mu \mathrm{l}$ stock until further use. The negative control group was prepared by the same way with brain suspension of uninfected 3-day-old suckling mice. $\mathrm{LD}_{50}$ of SRV9 in mice brain was $10^{-5.5}$, and all the experiments were performed with this stock.

Fluorescent antibody test (FAT) of RABV infected mouse brain tissues. The presence of RABV in the mice tissues was detected by a FAT method according to the reference (Appolinario et al., 2015). Brain samples were put on clean glass microscope slides and fixed overnight. Samples on slides were incubated with anti-rabies polyclonal antibody and then washed with buffer. After air-dry, coverslips were mounted on the slides and observed with a fluorescence microscope (Carl Zeiss AG, Germany). According to the fluorescence intensity, the results were classified as weak (30\% of the reference fluorescence), positive (60\% of the reference fluorescence) and strong (100\% of the reference fluorescence).

$R T$-PCR detection of RABV. The presence of RABV in the mice tissues was detected by the RT-PCR method according to the reference (Lopes et al., 2010). Following the manufacturer's protocol, rabies viral RNA was isolated from the central nervous system (CNS) and used for reverse transcription reaction. After reverse transcription, qRT-PCR was performed. The positive and negative controls were performed for all reactions. $\mathrm{P}<0.05$ was considered statistically significant.

Fluorescent antibody virus neutralization (FAVN) detection of anti-RABV neutralization antibody titer. The anti-RABV neutralization antibodies were detected in the peripheral blood obtained each day from infected suckling mice during 2 weeks after SRV9 inoculation. The antibody titer was determined by the FAVN method. FAVN detection was performed according to the reference (Wasniewski et al., 2014).

Determination of suckling mice morbidity. Suckling mice between 1 - and 22-day-old were divided into a group with at least 10 mice. After $300 \mathrm{LD}_{50} / 30 \mu \mathrm{l} /$ intracerebral injection of SRV9, the morbidity was recorded each day.

Grouping and sample preparation for proteomic analysis. There were 2 groups of suckling mice with 10 mice per group, 10- and 20 -day-old. In each group, 5 mice, were intracerebrally injected with SRV9 (300 $\left.\mathrm{LD}_{50} / 30 \mu \mathrm{l} / \mathrm{each}\right)$, and 5 uninfected mice were used as control. At $48 \mathrm{~h}$ after challenge, whole-brain tissue from 
10- and 20-day-old suckling mice were collected, and brain suspensions were prepared. The whole-brain tissues from infected and control mice were washed twice with pre-cooled sterile water to remove blood. After air dry, the tissues were ground 3 times with mortar and liquid nitrogen. Next, the ground tissues were placed in a $1.5 \mathrm{ml}$ Eppendorf tube and treated with $0.1 \mathrm{mg} / \mathrm{ml}$ of lysis solution (8M Urea, 2M Thiourea, $4 \%$ CHAPS, $40 \mathrm{mM}$ Tris, $0.5 \%$ IPG buffer). After repeated vortexing, the tissues were ultrasonicated until the liquid was clear and transparent. Finally, after 2 centrifugations at $14,000 \mathrm{xg}$ at $4^{\circ} \mathrm{C} 30 \mathrm{~min}$, the tissues were separated into tubes and cryopreserved in liquid nitrogen. The protein samples were purified by protein purification kit (2-D Clean-up kit, Pierce Biotechnology USA). The cryopreserved samples were quantified by protein assay kit (Bio-Rad Ettan 2-D quant kit, Bio-Rad, USA).

Two-dimensional gel electrophoresis (2-DE). For silver staining, we have used $150 \mu \mathrm{g}$ of total proteins of the sample and for Coomassie brilliant blue G250 staining $800 \mu$ g of total proteins. The sample was mixed with $3 \mu \mathrm{l}$ of IPG buffer, $7 \mu \mathrm{l} 1 \mathrm{M}$ DTT and water up to $350 \mu \mathrm{l}$. Next, the mixture was added to an $18 \mathrm{~cm}$ IPG gel linear $\mathrm{pH}$ $3-10$ strip. Initiative hydration was set at $20^{\circ} \mathrm{C}, 50 \mathrm{~V}$, for $14 \mathrm{~h}$, and then isoelectrofocusated (IEF). IEF was performed at $50 \mathrm{~V}$ for 14 h, $500 \mathrm{~V}$ for $1 \mathrm{~h}, 1000 \mathrm{~V}$ for $1 \mathrm{~h}, 3,000 \mathrm{~V}$ for $1 \mathrm{~h}, 8,000 \mathrm{~V}$ with linear rise to $64,000 \mathrm{~V}$ for $3 \mathrm{~h}$ at $50 \mu \mathrm{A} /$ gel. Otherwise, passive hydration was set for $24 \mathrm{~h}$, then transferred to IEF plate and focused at $250 \mathrm{~V}$ for $1 \mathrm{~h}, 500 \mathrm{~V}$ for $1 \mathrm{~h}, 1000 \mathrm{~V}$ for $1 \mathrm{~h}, 3,000 \mathrm{~V}$ for $1 \mathrm{~h}, 8,000 \mathrm{~V}$ with the linear rise to $64,000 \mathrm{~V}$ for $3 \mathrm{~h}$ at $50 \mu \mathrm{A} / \mathrm{gel}$. The IPG gel strip was incubated in reduction buffer for $15 \mathrm{~min}$ and alkylated in alkylation buffer for $15 \mathrm{~min}$. After two equilibrations, SDS-PAGE electrophoresis was performed. Electrophoresis conditions were $15 \mathrm{~mA} /$ gel at $16^{\circ} \mathrm{C}$ and after $1 \mathrm{~h} 30 \mathrm{~mA} /$ gel.

Gel staining. The SDS-PAGE gel was stained by silver staining. Firstly, it was immersed in $45 \%$ ethanol and $5 \%$ acetic acid solution and fixed for 20-30 min (or overnight). The gel was then washed 2 times for $3 \mathrm{~min}$ with water. Secondly, it was sensitized in $0.02 \%$ $\mathrm{Na}_{2} \mathrm{~S}_{2} \mathrm{O}_{3}$ for $30 \mathrm{~min}$ and then washed 3 times with water (5min). Thirdly, it was incubated in $0.1 \% \mathrm{AgNO}_{3}$ for $30 \mathrm{~min}$ and washed 3 times with water $(1 \mathrm{~min})$. Finally, it was developed in $2 \% \mathrm{Na}_{2} \mathrm{~S}_{2} \mathrm{O}_{3}$ solution containing $0.04 \%$ formaldehyde and terminated with EDTA-Na ${ }_{2}$ (3.65 g/250 ml double-distilled water). Colloidal blue staining. Firstly, the gel was immersed in a solution of $45 \%$ ethanol and 5\% acetic acid and fixed for 20-30 min, then washed 3 times with water for $2 \mathrm{~min}$. The gel was then stained with Colloidal blue (0.12\% G250) overnight and then distained.

Imaging and analysis. The gel was imaged by the scanner (Amersham Biosciences, USA, U9909H7L0, transmission, 256 gray-scale, $300 \mathrm{dpi}$, save *.TIF format). It was analyzed by ImageMaster 2D Platinum Software 6.0 (Amersham). The protein spots were taken as a significant differential expressing protein spots, of which samplecontrol proteins density ratio was $\geq 2$ times (up-regulation) or $\leq 0.5$ times (down-regulation) with T-test $(\mathrm{P}>0.05)$.

In-gel digestion. The differentially expressed protein spots were cut from the colloidal blue staining gel into $1 \mathrm{~mm}^{3}$ size pieces and put into an EP tube, repeatedly washed 3 to 4 times with deionized water to remove residual SDS. One to two hundred $\mu \mathrm{l}$ of destaining solution (50\% acetonitrile and $50 \% 50 \mathrm{mM} \mathrm{NH}_{4} \mathrm{HCO}_{3}$ solution) were added to the gel and shaken for $20 \mathrm{~min}$. The solution was discarded. Gel pieces were washed 1-2 times until transparent. Fifty $\mu \mathrm{l}$ of $10 \mathrm{mM}$ DTT stock solution was added to the gel and incubated at $56^{\circ} \mathrm{C}$ for $30 \mathrm{~min}$ and the reduction solution was discarded. One hundred $\mu \mathrm{l}$ of acetonitrile was added to dehydrate the gel for 5-10 min. Fifty $\mu \mathrm{l}$ of $55 \mathrm{mM}$ iodoacetamide solution was added to alkylate the gel for $30 \mathrm{~min}$, while protected from light. Alkylation solution was discarded, and the gel was immersed into 100 $\mu \mathrm{l}$ of a distaining solution and then washed 5-10 min with water. After distaining, the gel was put into vacuum dryer for $20 \mathrm{~min}$ for complete dehydration. Fifteen to twenty $\mu \mathrm{l}$ of trypsin $(0.01 \mu \mathrm{g} / \mu \mathrm{l})$ was added to the gel and incubated at $4^{\circ} \mathrm{C}$ for $30 \mathrm{~min}$. Then the remaining enzyme was discarded. Fifteen to twenty $\mu$ l of enzyme buffer $\left(25 \mathrm{mM} \mathrm{NH}_{4} \mathrm{HCO}_{3}\right.$ ) was added to the gel and incubated at $37^{\circ} \mathrm{C}$ for $15 \mathrm{~h}$ or overnight. Peptides were extracted with an enzyme solution and moved to a new EP tube. One hundred $\mu$ of extraction buffer I ( $5 \%$ TFA) was added into the original tube and heated at $40^{\circ} \mathrm{C}$ in the water bath for $45 \mathrm{~min}$, then ultrasonicated for $3 \mathrm{~min}$, and warmed in the water bath for $45 \mathrm{~min}$. Peptides were mixed with enzymolysis liquid - $100 \mu$ l of extraction buffer II ( $50 \%$ acetonitrile, 2.5\% TFA) and incubated at $30^{\circ} \mathrm{C}$ for $1 \mathrm{~h}$, followed by ultrasonication for $3 \mathrm{~min}$. The sample was dried, frozen and preserved at $-20^{\circ} \mathrm{C}$ for mass spectrometry.

Mass spectrometry. Using MALDI-TOF-MS/MS for analysis of ion mass-to-charge ratio scanning range of 800-4000 Da and 20 $\mathrm{kV}$ accelerated voltage, the high abundance of parent ions further formatted into ion fragments by collision-induced dissociation. Mass spectrometry internal standard was corrected and standardized by trypsin cleavage fragments. Based on peptide mass fingerprint (PMF) and tandem mass spectrometry (MS/MS), protein identification data were analyzed. Obtained mass spectrometry data were used for blasting in the NCBI non-redundant database of rodents based on MASCOT (Matrixscience, UK) search engine GPS software. Setting error parameter for the search of each peptide allows an error of a cleavage site and molecular mass error for a mass of $0.3 \mathrm{Da}$ and $0.4 \mathrm{Da}$ tandem mass spectrometry. Protein identification standard is the protein scored above 60 and the $95 \%$ confidence.

\section{Results} SRV9

Determination of death time of suckling mice infected by

In this study, we recorded the death time of mice after infection and used it for later analysis. The mortality of suckling mice inoculated intra-cerebrally with RABV SRV9 was $100 \%$ in 1-13-day-old mice, while there was no mortality in 18-22-day-old mice (Table 1.). 

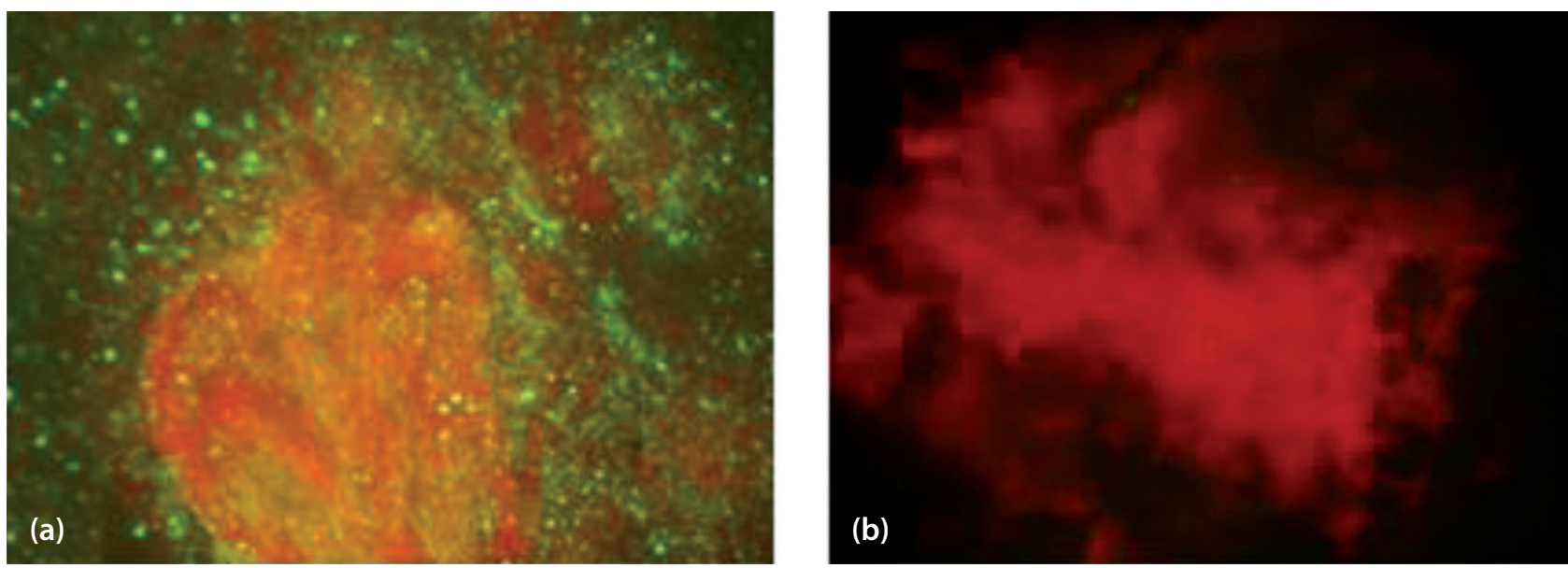

Fig. 1

The results of FAT

All the dead suckling mice brains were positive in FAT (a); negative control (b) (200x).

Table 1. The mortality of 1-21-day-old suckling mice infected with SRV9

\begin{tabular}{lcccccc}
\hline Age (days) & $1-13$ & 14 & 15 & 16 & 17 & $18-22$ \\
\hline Mortality (\%) & 100 & 68 & 33 & 33 & 17 & 0 \\
\hline
\end{tabular}

FAT and RT-PCR detection of rabies virus in brain tissue

To detect the presence of rabies virus in brain tissues of mice, we used FAT to detect the expression of proteins after the infection of rabies virus. According to the fluorescence intensity, the results were classified as weak (30\% of fluorescence of the reference), positive (60\%) and strong (100\%): The FAT detection results of all mouse brain tissues were positive (Fig. 1).

\section{The detection of rabies virus antibody titer}

The fluorescent antibody virus neutralization (FAVN) test is used for measurement of the response of an animal's immune system to the rabies vaccine. The test detects antiRABV neutralizing antibodies in peripheral blood serum. All surviving suckling mice after inoculation with SRV9 had present anti-RABV neutralization antibodies after 2 weeks.

\section{Results of 2-DE}

2-DE was used to conduct comparative proteomics analysis of the extracted proteins from brain samples of 4 mice groups (10- and 20-day-old SRV9 group, 10- and 20-dayold control group). To reduce the sample preparation error

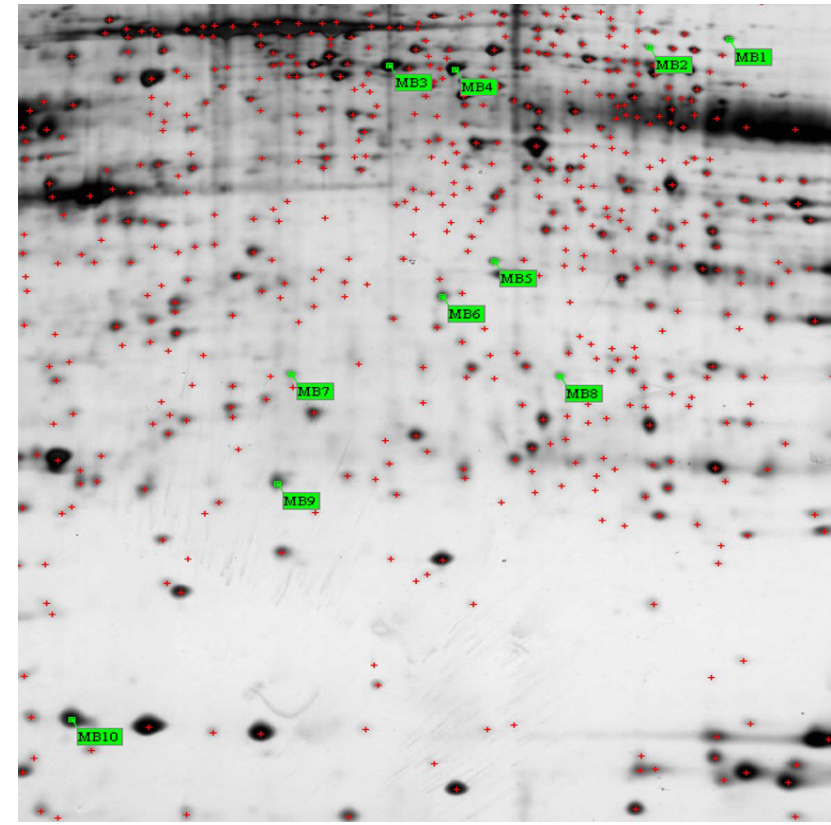

Fig. 2

2-DE image of proteins of the RABV SRV9 strain infected mouse brain sample

Signatures indicate spots with up- or down-regulation. Spots are numbered according to order in Table 3.

and the system error between the gels, these experiments were performed under the same conditions, including each infected and control group. After protein spots visualization, protein content was compared by ImageMaster 2D Platinum Software 6 software. In the results, up- or down-regulated expression levels of the protein spots varied more than 2 
Table 2. The quantitative results of suckling mouse brain protein samples

\begin{tabular}{lcccccccccccc}
\hline Group & \multicolumn{3}{c}{ 10-day-old SRV9 } & \multicolumn{3}{c}{ 10-day-old control } & \multicolumn{3}{c}{ 20-day-old SRV9 } & 20-day-old control \\
\hline Mouse number & $10 S 1$ & $10 S 2$ & $10 S 3$ & $10 \mathrm{Ct} 1$ & $10 \mathrm{Ct} 2$ & $10 \mathrm{Ct} 3$ & $20 \mathrm{~S} 1$ & $20 \mathrm{~S} 2$ & $20 \mathrm{~S} 3$ & $20 \mathrm{Ct} 1$ & $20 \mathrm{Ct} 2$ & $20 \mathrm{Ct} 3$ \\
Conc. $(\mu \mathrm{g} / \mathrm{ml})$ & 5767 & 6032 & 5357 & 7978 & 8420 & 8430 & 9279 & 9747 & 10060 & 8100 & 7456 & 6875 \\
\hline
\end{tabular}

Table 3. Differential protein expression in SRV9 -infected suckling mouse brain samples

\begin{tabular}{|c|c|c|c|c|c|c|c|c|c|}
\hline \multirow{2}{*}{ Index } & \multirow{2}{*}{ Protein name ${ }^{a}$} & \multirow{2}{*}{ Function clustering } & \multirow{2}{*}{ GI No. ${ }^{b}$} & \multirow{2}{*}{$\begin{array}{c}\mathrm{MM} \\
(\mathbf{k D a}) / \mathbf{p I}^{\mathrm{c}}\end{array}$} & \multirow{2}{*}{$\begin{array}{l}\text { Protein score/se- } \\
\text { quence coverage }^{\mathrm{d}}\end{array}$} & \multicolumn{4}{|c|}{ Ratio (group/10 control) ${ }^{e}$} \\
\hline & & & & & & $10 \mathrm{Ctrl}$ & $20 \mathrm{Ctrl}$ & 10 SRV9 & 20 SRV9 \\
\hline 1 & FUSE binding protein & Transcription regulator & gi|84662730 & $67.4 / 7.18$ & $1172 / 55 \%$ & 1.0 & 2.7 & 3.1 & 0.3 \\
\hline 2 & HnRP L & Transcription regulator & gi|20072624 & $60.1 / 6.65$ & $875 / 43 \%$ & 1.0 & 0.5 & 1.9 & 2.2 \\
\hline 3 & $\begin{array}{l}\text { dihydropyrimidinase-like } 3 \\
\text { isoforms } 2\end{array}$ & Neurobiology & gi|6681219 & $61.9 / 6.04$ & $2260 / 64 \%$ & 1.0 & 0.3 & 3.6 & 1.9 \\
\hline 4 & $\begin{array}{l}\text { dihydropyrimidinase-like } 3 \\
\text { isoforms } 2\end{array}$ & Neurobiology & gi|6681219 & $61.9 / 6.04$ & $2594 / 66 \%$ & 1.0 & 0.4 & 3.2 & 0.9 \\
\hline 5 & transaldolase 1 & $\begin{array}{l}\text { Synthesis and } \\
\text { degradation }\end{array}$ & gi|33859640 & $37.4 / 6.57$ & $958 / 56 \%$ & 1.0 & 1.9 & 2.2 & 2.3 \\
\hline 6 & $\begin{array}{l}\text { cytosolic malate } \\
\text { dehydrogenase }\end{array}$ & Signaling intermediates & gi|387129 & $36.4 / 6.16$ & $397 / 36 \%$ & 1.0 & 0.2 & 0.3 & 0.6 \\
\hline 7 & $\begin{array}{l}\text { haloacid dehalogenase-like } \\
\text { hydrolase }\end{array}$ & Enzyme & gi|21313310 & $28.7 / 5.70$ & $302 / 31 \%$ & 1.0 & 2.1 & 2.7 & 2.1 \\
\hline 8 & $\begin{array}{l}\text { A nmra-like family domain } \\
\text { containing } 1\end{array}$ & $\begin{array}{l}\text { Tumor suppressors/ } \\
\text { apoptosis }\end{array}$ & gi|24431937 & $34.4 / 6.37$ & $689 / 45 \%$ & $\mathrm{ND}^{\mathrm{f}}$ & 1.0 & 2.4 & 0.5 \\
\hline 9 & $\begin{array}{l}\text { NECAP endocytosis } \\
\text { associated } 1\end{array}$ & $\begin{array}{l}\text { Synthesis and } \\
\text { degradation }\end{array}$ & gi|27229051 & $29.6 / 5.97$ & $444 / 51 \%$ & 1.0 & 3.1 & 2.9 & 2.4 \\
\hline
\end{tabular}

$10 \mathrm{Ctrl}=10$-day-old suckling mice without infection; $20 \mathrm{Ctrl}=20$-day-old suckling mice without infection; 10 SRV9=10-day-old suckling mice infected

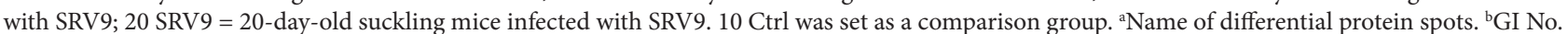
is the MASCOT results of MALDI-TOF-MS/MS searched from the NCBInr database. 'Theoretical molecular weight (kDa) and pI from the ExPASy database. ${ }^{\mathrm{d}}$ Protein score is probability-based MASCOT. Sequence coverage (\%) is the number of amino acids spanned by the assigned peptides divided by the sequence length. ${ }^{e}$ Levels of protein abundance in infected cells to that of uninfected cells. ${ }^{\mathrm{f}} \mathrm{ND}$, the protein spots were not detectable in the group.

folds, which were considered as significant differences. The results showed that at least 1000 protein spots were detected in each gel (Fig. 2), of which 10 protein spots with significant differential expression were selected for our study.

Identification of differentially expressed proteins with mass spectrometry

After the analysis with mass spectrometry, 8 unique proteins were identified from the 10 differentially expressed protein spots in 2-DE results. In the results, compared to 10-day-old control group, FUSE binding protein, HnRP L, dihydropyrimidinase-like 3 isoform 2 , dihydropyrimidinaselike 3 isoform 2, transaldolase 1, haloacid dehalogenase-like hydrolase, NmrA-like family domain containing 1 and NECAP endocytosis associated 1 were up-regulated and cytosolic malate dehydrogenase was down-regulated in the group of 10-day-old SRV9 group $(\mathrm{P}<0.05)$, which is shown in Table 3 and Fig. 2. We set the $10 \mathrm{Ctrl}$ as compare group, and selected these differential expression proteins to do GO clustering for categorization which is shown in Table 3.

\section{Discussion}

The rabies virus SRV9 strain is an attenuated strain. In our previous study, we found that when the strain with $300 \mathrm{LD}_{50} / 30 \mu \mathrm{l}$ was injected intracerebrally into mice it caused $100 \%$ mortality in mice under 13 days of age, partial mortality of suckling mice under 14-17 days of age, while no suckling mice older than 18 days died. We did all the experiments under the same conditions, with differences in mice age, which lead to differences in mice mortality. We investigated the mechanisms of virus-host interactions by proteomics methods. Proteomics is one of the powerful tools to find disease-related proteins and reveal the mechanisms of pathogenicity. In the research of viral infection, proteomics can be used as an important tool to study protein abundance 


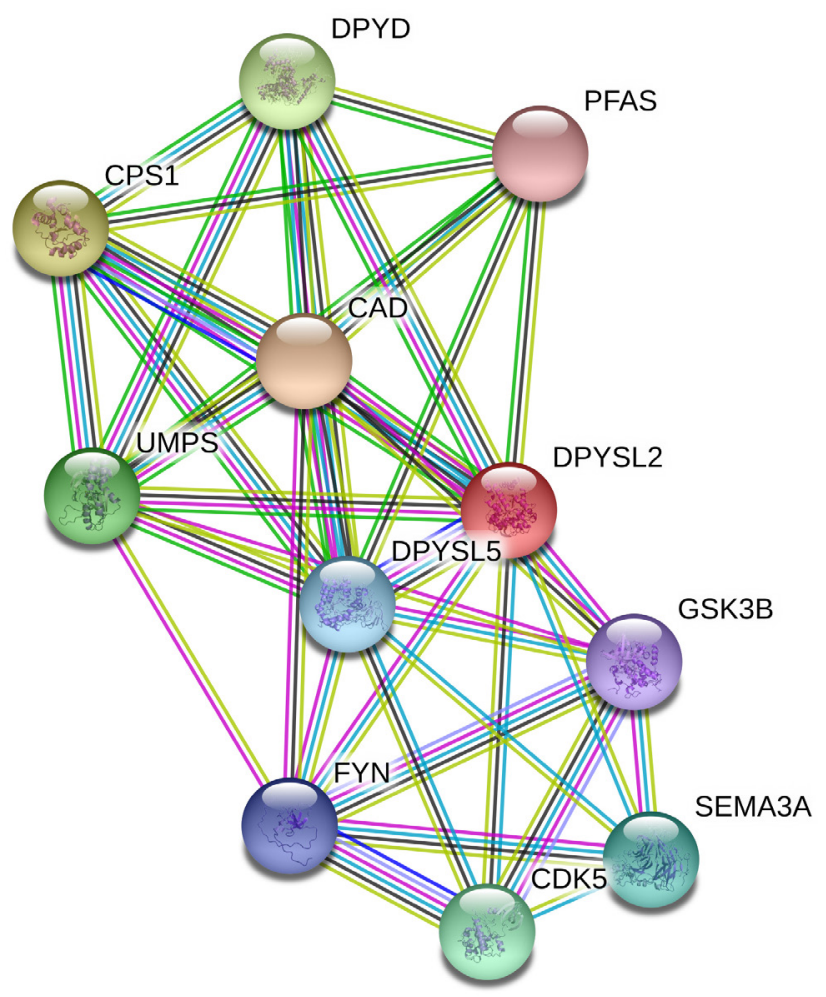

Fig. 3

Proteins which show a potential connection with DPYSL analyzed by string software

in tissues or cells at different infection stages. The twodimensional gel electrophoresis (2-DE), mass spectrometry (MS) identification and analysis in protein database can be used for proteomics analysis (Banki et al., 1996).

To investigate host proteins involved in the RABV infection, rabies virus strain SRV9 was used to infect suckling mice and brain tissues from these mice were collected to conduct differential proteomics. In our study, we selected SRV9 strain because it showed good cell adaptability after the long-term cell culture. $\mathrm{TCID}_{50}$ of the virus cultured in BHK cells is $10^{7}$, so the SRV9 strain has a good prospect in the inactivated vaccine, especially oral live attenuated vaccine research.

As mentioned before, SRV9 still has strong pathogenicity to low ages of suckling mice. If we can get differential protein abundance profiles of the brain tissue of infected suckling mice before and after death age, it will provide the basis to understand the mechanism of RABV infection, especially susceptibility to SRV9 in the mice at different ages. Using two-dimensional electrophoresis, we analyzed proteomics of differential protein abundance in 10- and 20-day-old suckling mice brains infected with rabies virus attenuated vaccine SRV9 strain. The results showed that the expressions of 10 protein spots had at least been 2 -fold up- or down-regulated.
Using MALDI-TOF-MS, we identified 8 proteins from these 10 spots. Among these unidentified proteins, 1 spot failed to be identified due to low protein content and failure to produce good mass spectrometry data. After analysis, we hypothesize that those differentially expressed proteins may be closely related to the susceptibility of SRV9 in different ages of suckling mice.

Those differentially expressed proteins play important roles in some cellular functions. Their differences may be related to the response of SRV9 in suckling mice. Differentially expressed proteins are FUSE binding protein, heterogeneous nuclear ribonucleoprotein L (HnRNP L), dihydropyrimidinase-like 3 isoform 2 , dihydropyrimidinaselike 3 isoform 2 transaldolase 1, cytosolic malate dehydrogenase, haloacid dehalogenase-like hydrolase, NmrA-like family domain containing 1, NECAP endocytosis associated 1, far upstream element (FUSE) binding protein (FBP). Some studies show that FBP can regulate the expression of proteins through binding with the 5 end of the $c$-Myc gene (Tremolada et al., 2008). The $c-M y c$ gene can encode a c-Myc protein which is involved in a series of cellular activities, including cell proliferation, differentiation and cell cycle, and tumor formation. Due to the activation of the $c-M y c$ gene, the expression level of $\mathrm{c}-\mathrm{Myc}$ protein in many tumor tissues and cell tumorigenesis was increased. c-Myc protein is also associated with cell apoptosis. Some studies proved that the differential expression level of c-Myc protein in cells could induce apoptosis (Thompson, 1998). The transcription of the $c-M y c$ gene was strictly controlled by many transcription factors, and FBP is one of the important factors. The Far upstream element (FUSE) is located at $1.5 \mathrm{~kb}$ upstream of the transcription start site of the $c-M y c$ gene, and FBP could bind to these sites and regulate the transcription of c-Myc (Avigan et al., 1990). Until now, three kinds of FBP, i.e. FBP, FBP2, and FBP3 were found (He et al., 2000). FBP regulates the transcription process, and some reports showed that FBP and its relatives FBP2 and FBP3 can interact with some RNA molecules to participate in the transcription, transmission, and degradation of RNA in the cytoplasm or nucleus (Davis-Smyth et al., 1996). In this experiment, the expression of FBP was up-regulated in the RABV infected suckling mouse at 10 days of age while the expression of FBP was down-regulated in the RABV infected suckling mice at 20 days of age. Besides, the expression of FBP was up-regulated in adult mice infected by RABV virulent strains, but we do not know the reasons for increased or decreased expression of FBP in RABV. It needs further investigation to identify whether RABV infection affects the c-Myc pathway.

HnRNP L protein belongs to the hnRNPs (heterogeneous nuclear ribonucleoprotein) family. hnRNPs is a nuclear RNA binding protein, which is involved in transcription, mRNA transportation, and splicing, mRNA stability, telomere length control and mRNA polyadenylation (Krecic et al., 
1999). hnRNP L also plays a key role in viral infection. For example, the 3 ' end ribosome entry position of the hepatitis $\mathrm{C}$ virus (IRES) is an important regulation site of viral translation. hnRNP L was found to be involved in the regulation of this site (Harris et al., 2006). The interaction of HnRNP $\mathrm{L}$ and HCV IRES improved the efficiency of hepatitis B virus mRNAs translation and increased viral genes expression. HnRNP A1 was found to bind the 3' end of the plus strand and minus strand of mouse hepatitis virus (MHV) RNA, which regulates the synthesis of viral RNA (Li et al., 1997; Wang et al., 1999; Zhang et al., 1999). This function of HnRNP A1 could be replaced by other closely related hnRNP proteins (Shi et al., 2003). Several hnRNP proteins are involved in the synthesis and processing of viral RNA. For example, hnRNP A1 participates in the replication of hepatitis $\mathrm{C}$ virus (HCV) and binds to the $5^{\prime}$ end ( $\left.5^{\prime} \mathrm{NTR}\right)$ and $3^{\prime}$ end untranslated region ( $3^{\prime} \mathrm{NTR}$ ) of NS5b protein and viral genome, which are necessary for viral replication, and reduce the replication of HCV to knockout hnRNP A1 of host cells (Valente et al., 2006). The function of HnRNP A1 involved in MHV RNA synthesis might be also replaced by other closely related hnRNP protein (Denes et al., 2006). Besides, several kinds of hnRNP proteins are involved in the regulation of RNA metabolism and gene expression of the human immunodeficiency virus (HIV) (Johnson et al., 2006; Kumaraswamy et al., 2006; Wang et al., 2005). Some studies indicate that the expression levels of four hnRNPs or its related proteins change in PK-15 cells infected by CSFV, suggesting that CSFV replication might need the participation of hnRNPs in host cells (Sun et al., 2008). In our experiment, we also found that the expression of hnRNP K was up-regulated in the group of infected mice with three strains of RABV with different virulence and cell compatibility, as compared with the control group. We also found that hnRNP $\mathrm{L}$ is up-regulated in the 10- or 20-day-old mice infected by SRV9 for $48 \mathrm{~h}$, indicating that hnRNP L might modulate the response and proliferation of RABV in the infected cells.

Transaldolase (TAL.EC2.2.1.2) is the key enzyme in the non-oxidative phase of the pentose phosphate pathway (Pentose Phosphate Pathway). It can keep the balance at the oxidative and non-oxidative phase of the pentose phosphate pathway to generate 5-ribose phosphate and NADPH (nicotinamide adenine dinucleotide phosphate) (Wood, 1972). 5-ribose phosphate is the precursor substance of the nucleotide coenzyme $\mathrm{A}, \mathrm{NAD}+$ (nicotinamide adenine dinucleotide phosphate) and other molecules; and NADPH can maintain the reduction state of glutathione to protect the integrity of thiol and cell membrane from the damage caused by oxygen free radicals. It also can serve as the hydrogen donor and directly be involved in various metabolic reactions. Banki (1996) research group used transaldolase sense and antisense carrier to transfect Jurkat cell line. Their results show that the excessive expression of transaldolase could reduce the activity of 6-phosphate glucose dehydrogenase and 6-phosphogluconate dehydrogenase and increase the yield of NADPH, which leads to the generation of reactive oxygen intermediates, increase of mitochondrial transmembrane potential, activation of asparagus enzyme, overturn of phosphatidylserine and acceleration of cell apoptosis process. Also, they proved that the transfected cells are highly sensitive to hydrogen peroxide, nitric oxide, tumor necrosis factor, and other apoptosis factors. While in the antisense transfection group the expression of transaldolase was inhibited and the results were just the opposite. (Banki et al., 1996). Transaldolase can regulate cell apoptosis, which might be caused by differential transaldolase positive catalytic and reverse catalytic rate. In transaldolase sense transfection group, excessive transaldolase expression increased reverse catalytic activity and decreased the generation of 6-phosphate-glucose. Later the substrate of 6-phosphate-glucose dehydrogenase inhibited its activity, thereby decreasing the production of NADPH and inducing apoptosis. In recent years, research showed that transaldolase plays an important role in lymphocyte apoptosis (Banki et al., 1998), malignant tumors (Lachaise et al., 2001), organ development (Urner et al., 1999) embryonic development (Heinrich et al., 1976) and it also can be induced by human immunodeficiency virus (HIV) ) (Valente et al., 2006). The expression and activity of transaldolase show obvious tissue specificity, development phase correlation and difference between physiological and pathological conditions. In our study, SRV9 infection upregulated transaldolase expression in 10-day-old mice, while there was no significant change of the transaldolase expression level in 20-day-old mice infected by SRV9. Considering the physiological function of transaldolase, the result may provide evidence for different pathogenicity of SRV9 in the differential growth phase of suckling mice.

DPYSL3 is a member of the TUC (TOAD-64/ULIP/ CRMP) protein family, which is also called the dihydropyrimidinase related protein 3 (DRP-3), brain failure collapsin response-mediated protein 4 (CRMP-4), TUC-4 or Ulip-1 (Quinn et al., 1999). DPYSL3 is a protein which can regulate the development and can be efficiently expressed in postmitotic neurons in the early embryo, and the expression level of DPYSL3 reaches the peak in one week after delivery (Charrier et al., 2003). In the adult brain, DPYSL3 mainly exists in the conserved area of neurogenesis such as dentate gyrus granule neurons, or area with axonal growth and synaptic rearrangements such as glomeruli, piriform cortex, and hypothalamus (Byk et al., 1998; Nacher et al., 2000). Also, the DPYSL3 protein was found in the binding site of the neuromuscular junction and its main function is to maintain the stability of neural cells (Bourhy et al., 1992). The neurotropism of DPYSL protein, especially those abundant in nitrite and axon growth cone body, participated in neural differentiation and the growth of axon (Charrier et al., 2003). 
Also, DPYSL3 proteins may be related to the regeneration of nerve cells (Minturn et al., 1995). In our results, we found that the expression of DPYSL3 protein in normal 10-day-old suckling mice was significantly higher than in 20-day-old mice. It was also significantly up-regulated regardless of 10or 20-day-old mice infected with SRV9 for $48 \mathrm{~h}$, indicating that SRV9 infection induced the up-regulation expression of DPYSL3 in mice. DPYSL3 protein is the only protein which is not only related to the growth and development but also is related to the neurons. However, we still don't know the reasons and we need to investigate this topic further. NECAPs (adaptin ear-binding clathrin-associated protein) is a class of new clathrin auxiliary protein family determined by proteomic analysis through the coated vesicles in clathrincoated vesicles (CCVs). NECAP 1 is the most important protein in this family (Blondeau et al., 2004). NECAP 1 mainly exists in the tissues of the central nervous system and participates in endocytosis. Part of the protein within the caveolae coated by clathrin can directly bind with the spherical ear domain of a cohesion subunit ( $a$ ear) of adaptor protein 2 (AP-2) to form dense adaptor protein complex (Ritter et al., 2003). AP2 is the adapter protein specifically involved in the transformation from the cytoplasmic membrane to the endosomes (Kirchhausen, 2002) and it can promote the aggregation of NECAP 1 and other auxiliary proteins (Ritter et al., 2007). NECAP 1 is recruited in invaginating vesicles in the presence of AP2 and guides the aggregation of clathrin to multimerize into a grid and draw the membrane to the cytoplasm to form the coated vesicle (Schmid, 1997). The clathrin-coated vesicles mediate endocytosis internalization. In the synapse, the recycling of synaptic vesicles happens mainly through the endocytosis with the involvement of NECAP 1 mediated by clathrin (Blondeau et al., 2004; Takei et al., 1996). NECAP 1 is another protein found in this study to be closely related to the nervous system. At present, we still do not know its function, but the RABV neurotropism has been verified in the experiment comprehensively.

Nitrogen metabolite repression regulator $(\mathrm{NmrA})$ is a transcription repressor with a negative regulatory role in Aspergillus nidulans, fungi and nitrogen metabolism. It belongs to the short-chain dehydrogenase reductase superfamily (SDR) (Stammers et al., 2001). X-ray crystal diffraction results indicate that $\mathrm{NmrA}$ consists of two domains: Rossmann folding domain in $\mathrm{N}$ end ( $\beta \alpha \beta \alpha \beta$ structure) and GATA type zinc finger structure in the $C$ terminus. The zinc-finger structure contributes to the formation of proteinprotein or protein-DNA complex (Davis et al., 1987; Fu et al., 1990; Marzluf, 1997). NMR is a monomeric protein without complete nucleic acid binding motif of the SDR family. It is also without the enzyme activity of other proteins of the SDR family, but it can form reduction type structure binding with $\mathrm{NAD}+$. In addition, it can regulate the nitrogen metabolism process together with the zinc finger structure in the $\mathrm{C}$ terminus of AreA protein, which belongs to the same family with SDR. According to the structural characteristics of NmrA and other SDR family members, they were considered as the ideal pharmacological target to treat many diseases, including metabolic diseases and some infectious diseases (Oppermann et al., 2003). However, the function of the protein with differential expression level in suckling mice infected with SRV9 is not clear. In previous experiments, we used three strains of RABV with different cell adaptive capacities to infect cell lines in vitro and the results showed that Zfp12 protein is a zinc finger-related protein. In this experiment, the differentially expressed protein transaldolase is also involved in NAD+ metabolism. It points to the fact that NAD+ metabolism in the host may play an important role in the SRV9 infection. However, whether there is a link between transaldolase and NmrA-Zfp12 protein during RABV infection needs to be further investigated.

Cytosolic malate dehydrogenase (cyMDH) is widely present in animals, plants, and microorganisms and shows high conservation in different species. It mainly catalyzes the mutual conversion between oxaloacetate and malate. cyMDH plays an important role in many shuttle systems of cytoplasm and organelles (Ding et al., 2004) and also has an important impact on the nucleic acid selective channels and gluconeogenesis (Gibson et al., 2003). In addition, cyMDH is also the key enzyme in malic acid metabolism and coordinates the phosphoenolpyruvate carboxylase (PEPC) to maintain malic acid in the cytoplasm (Chollet et al., 1996). It shows differential expression level in our experiment which indicates that SRV 9 infection impacts the nucleic acid pathway in the host cell. More details should be investigated in the future.

In conclusion, this experiment revealed the differential expression protein situation in the brain tissues of 10 - and 20-day-old suckling mice infected with SRV9 compared to uninfected suckling mice. Eight proteins were differentially expressed, of which the differential expression of hnRNP L, DPYSL3, NECAPs, and transaldolase might be closely related to the susceptibility of suckling mice of different ages to SRV9. DPYSL is the differential expression protein with a high score, and we want to investigate it further. All of these results can provide us the crucial basis for the detailed mechanism by which rabies infects the host, and can help us find a solution for the treatment of rabies virus.

Acknowledgment. This study was supported, in part, by grants from the Guangzhou Science Technology and Innovation Commission (No. 201707010153, No. 201909020001), Natural Science Foundation of Guangdong Province (No. 2017A030313094, No. 2017A030310091), and the National Natural Science Foundation of China (No. 31201918). 


\section{References}

Appolinario C, Allendorf SD, Vicente AF, Divide Ribeiro B, da Fonseca CR, Antunes JM, Peres MG, Kotait I, Carrieri ML, Megid J (2015): Fluorescent antibody test, quantitative polymerase chain reaction pattern and clinical aspects of rabies virus strains isolated from main reservoirs in Brazil. The Brazilian Journal of Infectious Diseases: an official publication of the Brazilian Society of Infectious Diseases. https://doi.org/10.1016/j.bjid.2015.06.012

Avigan MI, Strober B, Levens D (1990): A far upstream element stimulates c-Myc expression in undifferentiated leukemia cells. J. Biol. Chem. 265, 18538-18545.

Banki K, Perl A (1996): Inhibition of the catalytic activity of human transaldolase by antibodies and site-directed mutagenesis. FEBS Letters 378, 161-165. https://doi.org/10.1016/00145793(95)01446-2

Banki K, Hutter E, Gonchoroff NJ, Perl A (1998): Molecular ordering in HIV-induced apoptosis. Oxidative stress, activation of caspases, and cell survival are regulated by transaldolase. J. Biol. Chem. 273, 11944-11953. https:// doi.org/10.1074/jbc.273.19.11944

Blondeau F, Ritter B, Allaire PD, Wasiak S, Girard M, Hussain NK, Angers A, Legendre-Guillemin V, Roy L, Boismenu D, Kearney RE, Bell AW, Bergeron JJ, McPherson PS (2004): Tandem MS analysis of brain clathrin-coated vesicles reveals their critical involvement in synaptic vesicle recycling. PNAS USA 101, 3833-3838 https://doi. org/10.1073/pnas.0308186101

Bourhy H, Kissi B, Lafon M, Sacramento D, Tordo N (1992): Antigenic and molecular characterization of bat rabies virus in Europe. J. Clin. Microbiol. 30, 2419-2426.

Byk T, Ozon S, Sobel A (1998): The Ulip family phosphoproteins-common and specific properties. European journal of biochemistry / FEBS 254, 14-24. https://doi.org/10.1046/ j.1432-1327.1998.2540014.x

Charrier E, Reibel S, Rogemond V, Aguera M, Thomasset N, Honnorat J (2003): Collapsin response mediator proteins (CRMPs): involvement in nervous system development and adult neurodegenerative disorders. Mol. Neurobiol. 28, 51-64. https://doi.org/10.1385/MN:28:1:51

Chollet R, Vidal J, O'Leary MH (1996): Phosphoenolpyruvate carboxylase: A ubiquitous, highly regulated enzyme in plants. Annu. Rev. Plant Physiol. Plant Mol. Biol. 47, 273-298. https://doi.org/10.1146/annurev.arplant.47.1.273

Davis-Smyth T, Duncan RC, Zheng T, Michelotti G, Levens D (1996): The far upstream element-binding proteins comprise an ancient family of single-strand DNA-binding transactivators. J. Biol. Chem. 271, 31679-31687. https:// doi.org/10.1074/jbc.271.49.31679

Davis MA, Hynes MJ (1987): Complementation of areA- regulatory gene mutations of Aspergillus nidulans by the heterologous regulatory gene nit-2 of Neurospora crassa. PNAS USA 84, 3753-3757. https://doi.org/10.1073/ pnas.84.11.3753

Denes A, Boldogkoi Z, Hornyak A, Palkovits M, Kovacs KJ (2006): Attenuated pseudorabies virus-evoked rapid innate im- mune response in the rat brain. J. Neuroimmunol. 180, 88-103. https://doi.org/10.1016/j.jneuroim.2006.07.008

Ding Y, Ma QH (2004): Characterization of a cytosolic malate dehydrogenase cDNA which encodes an isozyme toward oxaloacetate reduction in wheat. Biochimie 86, 509-518. https://doi.org/10.1016/j.biochi.2004.07.011

Fu YH, Marzluf GA (1990): Nit-2, the major positive-acting nitrogen regulatory gene of Neurospora crassa, encodes a sequence-specific DNA-binding protein. PNAS USA 87, 5331-5335. https://doi.org/10.1073/pnas.87.14.5331

Gibson N, McAlister-Henn L (2003): Physical and genetic interactions of cytosolic malate dehydrogenase with other gluconeogenic enzymes. J. Biol. Chem. 278, 25628-25636. https://doi.org/10.1074/jbc.M213231200

Harris D, Zhang Z, Chaubey B, Pandey VN (2006): Identification of cellular factors associated with the 3'-the nontranslated region of the hepatitis $\mathrm{C}$ virus genome. Mol. Cell Proteomics 5, 1006-1018. https://doi.org/10.1074/mcp. M500429-MCP200

He L, Liu J, Collins I, Sanford S, O'Connell B, Benham CJ, Levens D (2000): Loss of FBP function arrests cellular proliferation and extinguishes c-myc expression. The EMBO J. 19, 1034-1044. https://doi.org/10.1093/emboj/19.5.1034

Heinrich PC, Morris HP, Weber G (1976): Behavior of transaldolase (EC 2.2.1.2) and transketolase (EC 2.2.1.1) Activities in normal, neoplastic, differentiating, and regenerating liver. Cancer Res. 36, 3189-3197.

Johnson N, McKimmie CS, Mansfield KL, Wakeley PR, Brookes SM, Fazakerley JK, Fooks AR (2006): Lyssavirus infection activates interferon gene expression in the brain. J. Gen. Virol. 87, 2663-2667. https://doi.org/10.1099/ vir.0.82024-0

Kirchhausen T (2002): Clathrin adaptors really adapt. Cell 109: 413-416. https://doi.org/10.1016/S0092-8674(02)00751-1

Krecic AM, Swanson MS (1999): hnRNP complexes: composition, structure, and function. Curr. Opin. Cell Biol. 11, 363-371. https://doi.org/10.1016/S0955-0674(99)80051-9

Kumaraswamy GK, Fu MM, Docherty JJ (2006): Innate and adaptive host response during the initial phase of herpes simplex virus encephalitis in the neonatal mouse. J. Neurovirol. 12, 365-374. https://doi.org/10.1080/13550280600970417

Lachaise F, Martin G, Drougard C, Perl A, Vuillaume M, Wegner M, Sarasin A, Daya-Grosjean L (2001): Relationship between posttranslational modification of transaldolase and catalase deficiency in UV-sensitive repair-deficient xeroderma pigmentosum fibroblasts and SV40-transformed human cells. Free Radic. Biol. Med. 30, 1365-1373. https://doi. org/10.1016/S0891-5849(01)00532-9

Li HP, Zhang X, Duncan R, Comai L, Lai MM (1997): Heterogeneous nuclear ribonucleoprotein $\mathrm{A} 1$ binds to the transcription-regulatory region of mouse hepatitis virus RNA. PNAS USA 94, 9544-9549. https://doi.org/10.1073/ pnas.94.18.9544

Lopes MC, Venditti LL, Queiroz LH (2010): Comparison between RT-PCR and the mouse inoculation test for detection of rabies virus in samples kept for long periods under different conditions. J. Virol. Methods 164, 19-23. https:// doi.org/10.1016/j.jviromet.2009.11.017 
Marzluf GA (1997): Genetic regulation of nitrogen metabolism in the fungi. Microbiol. Mol. Biol. Rev. 61, 17-32.

Minturn JE, Fryer HJ, Geschwind DH, Hockfield S (1995): TOAD64 , a gene expressed early in neuronal differentiation in the rat, is related to unc-33, a C. elegans gene involved in axon outgrowth. J. Neurosci. 15, 6757-6766. https://doi. org/10.1523/JNEUROSCI.15-10-06757.1995

Muller T, Selhorst T, Burow J, Schameitat A, Vos A (2006): Crossreactive antigenicity in orally vaccinated foxes and raccoon dogs against European Bat Lyssavirus type 1 and 2. Dev. Biol. 125, 195-204.

Nacher J, Rosell DR, McEwen BS (2000): Widespread expression of rat collapsin response-mediated protein 4 in the telencephalon and other areas of the adult rat central neRABVous system. J. Comp. Neurol. 424, 628-639. https:// doi.org/10.1002/1096-9861(20000904)424:4<628::AIDCNE5 > 3.0.CO;2-4

Oppermann U, Filling C, Hult M, Shafqat N, Wu X, Lindh M, Shafqat J, Nordling E, Kallberg Y, Persson B, Jornvall H (2003): Short-chain dehydrogenases/reductases (SDR): the 2002 update. Chem.-Biol. Interact. 143-144, 247-253. https://doi.org/10.1016/S0009-2797(02)00164-3

Pleissner KP, Eifert T, Buettner S, Schmidt F, Boehme M, Meyer TF, Kaufmann SH, Jungblut PR (2004): Web-accessible proteome databases for microbial research. Proteomics 4, 1305-1313. https://doi.org/10.1002/pmic.200300737

Quinn CC, Gray GE, Hockfield S (1999): A family of proteins implicated in axon guidance and outgrowth. J. Neurobiol. 41, 158-164. https://doi.org/10.1002/(SICI)10974695(199910)41:1<158::AID-NEU19>3.0.CO;2-0

Ritter B, Philie J, Girard M, Tung EC, Blondeau F, McPherson PS (2003): Identification of a family of endocytic proteins that define a new alpha-adaptin ear-binding motif. EMBO reports 4, 1089-1095. https://doi.org/10.1038/ sj.embor.7400004

Ritter B, Denisov AY, Philie J, Allaire PD, Legendre-Guillemin V, Zylbergold P, Gehring K, McPherson PS (2007): The NECAP PHear domain increases clathrin accessory protein binding potential. EMBO J. 26, 4066-4077. https://doi. org/10.1038/sj.emboj.7601836

Schmid SL (1997): Clathrin-coated vesicle formation and protein sorting: an integrated process. Ann. Rev. Biochem. 66, 511-548. https://doi.org/10.1146/annurev.biochem.66.1.511

Schmidt CS, White CJ, Ibrahim AS, Filler SG, Fu Y, Yeaman MR, Edwards JE, Jr., Hennessey JP, Jr. (2012): NDV-3, a recombinant alum-adjuvanted vaccine for Candida and Staphylococcus aureus, is safe and immunogenic in healthy adults. Vaccine 30, 7594-7600. https://doi. org/10.1016/j.vaccine.2012.10.038

Shi ST, Yu GY, Lai MM (2003): Multiple type A/B heterogeneous nuclear ribonucleoproteins (hnRNPs) can replace hnRNP A1 in mouse hepatitis virus RNA synthesis. J. Virol. 77, 10584-10593. https://doi.org/10.1128/JVI.77.19.10584$\underline{10593.2003}$
Stammers DK, Ren J, Leslie K, Nichols CE, Lamb HK, Cocklin S, Dodds A, Hawkins AR (2001): The structure of the negative transcriptional regulator NmrA reveals a structural superfamily which includes the short-chain dehydrogenase/reductases. EMBO J. 20, 6619-6626. https://doi. org/10.1093/emboj/20.23.6619

Sun J, Jiang Y, Shi Z, Yan Y, Guo H, He F, Tu C (2008): Proteomic alteration of PK-15 cells after infection by classical swine fever virus. J. Prot. Res. 7, 5263-5269. https://doi. org/10.1021/pr800546m

Takei K, Mundigl O, Daniell L, De Camilli P (1996): The synaptic vesicle cycle: a single vesicle budding step involving clathrin and dynamin. J. Cell Biol. 133, 1237-1250. https://doi. org $/ 10.1083 /$ jcb.133.6.1237

Thompson EB (1998): The many roles of c-Myc in apoptosis. Ann. Rev. Physiol. 60, 575-600. https://doi.org/10.1146/annurev.physiol.60.1.575

Tremolada S, Delbue S, Ferrante P (2008): [Viral infections of the fetus and newborn infant]. La Pediatria medica e chirurgica: Med. Surg. Pediatrics 30, 177-191.

Urner F, Sakkas D (1999): Characterization of glycolysis and pentose phosphate pathway activity during sperm entry into the mouse oocyte. Biol. Reprod. 60, 973-978. https://doi. org/10.1095/biolreprod60.4.973

Valente ST, Goff SP (2006): Inhibition of HIV-1 gene expression by a fragment of hnRNP U. Mol. Cell 23, 597-605. https:// doi.org/10.1016/j.molcel.2006.07.021

Wang Y, Zhang X (1999): The nucleocapsid protein of coronavirus mouse hepatitis virus interacts with the cellular heterogeneous nuclear ribonucleoprotein $\mathrm{A} 1$ in vitro and in vivo. Virology 265, 96-109. https://doi.org/10.1006/ viro.1999.0025

Wang ZW, Sarmento L, Wang Y, Li XQ, Dhingra V, Tseggai T, Jiang B, Fu ZF (2005): Attenuated rabies virus activates, while pathogenic rabies virus evades, the host innate immune responses in the central neRABVous system. J. Virol. 79, 12554-12565. https://doi.org/10.1128/JVI.79.19.12554$\underline{12565.2005}$

Wasniewski M, Barrat J, Combes B, Guiot AL, Cliquet F (2014): Use of filter paper blood samples for rabies antibody detection in foxes and raccoon dogs. J. Virol. Methods 204, 11-16. https://doi.org/10.1016/j.jviromet.2014.04.005

Wenqiang J, Yin X, Lan X, Li X, Liu J (2014): Development of a reverse genetics system for the $\mathrm{aG}$ strain of rabies virus in China. Arch. Virol. 159, 1033-1038. https://doi. org/10.1007/s00705-013-1919-9

Wood T (1972): The forward and reverse reactions of transaldolase. FEBS Letters 25, 153-155. https://doi.org/10.1016/00145793(72)80474-5

Zhang X, Li HP, Xue W, Lai MM (1999): Formation of a ribonucleoprotein complex of mouse hepatitis virus involving heterogeneous nuclear ribonucleoprotein $\mathrm{A} 1$ and transcription-regulatory elements of viral RNA. Virology 264, 115-124. https://doi.org/10.1006/viro.1999.9970 